\title{
Two Cases of Uterine Fibroid Showing Perithelio- matous changes: Long Immunity from Recur- rence after Operation.*
}

\author{
$\mathbf{B X}$ \\ Alban H. G. Doran, F.R.C.S., \\ Senior Surgeon, Samaritan Free Hospital, \\ AND \\ Cuthbert Lockyer, M.D., F.R.C.S., \\ Senior Physician to Out-patients, Samaritan Free Hospital.
}

Now, when hysterectomy for fibromyoma of the uterus is performed widely and with great success, the question of the possibility of malignant elements lying concealed in an innocent-looking tumour of this familiar type has become of high importance. $\dagger$ Kynoch $\ddagger$ describes a successful supravaginal hysterectomy for the removal of a bleeding fibroid: the patient was 48 years of age. The parts removed were put aside, very fortunately. Nearly a year later, a hard new growth, of the size of an orange, was removed from the anterior aspect of the right elbow. Then, for the first time, the fibroid was examined microscopically. Distinct sarcomatous degeneration was detected in its substance, and the secondary tumour proved to be a sarcoma of the same type. The patient died six months after the second operation, with metastatic deposits in the abdomen. Many similar cases must have been overlooked.

Circumstances were quite different in the two cases which we now* bring forward. In both, Mr. Doran, the operator, suspected that the fibroid was very malignant when he amputated the uterus. So it was with Dr. W. C. Swayne's cases, recently discussed before this Section. In both, Dr. Lockyer examined the tumour microscopically and detected what was histologically a true maliguant change. Month by month after each operation the operator expected to hear bad news, and he actually received a false report about the death of the second patient, which for a time completely misled him.

* Read at a meeting of the Obstetrical and Gynæcological Section of the Royal Society of Medicine, October 8th, 1908.

t The literature of the subject is voluminous. For a convenient summary, see Kelly and Noble, Gynecology and Abdominal Surgery (1907), p. 669 . Sarcomatous degeneration was detected in 34 out of 2,274 cases (1.4 per cent.) of uterine fibroid in their statistics.

‡"Zwei Fälle von malignen Fibromyom des Uterus," Archiv f. Gynäk,, vol. lxxxii, p. 254 . 
Nevertheless, the first patient is living four and a half years after the operation, and has grown stout, and the second visited the operator over a year after her reported death and proved to be in good health and free from any evidence of recurrence two years and seven months after a hysterectomy, which seemed to him at the time to be sadly incomplete.

CASE I. Cystic uterine fibroid of large size, in a quintipara aged 49. Infection of a loculus after tapping. Fibroma of ovary. Supravaginal hysterectomy: removal of the fibromatous ovary. Opposite Fallopian tube and ovary not removed. Uterine tumour malignant (perithelioma) according to microscopic appearances. Convalescence protracted through infection probably from the tapped loculus. Speedy recurrence expected: yet patient living and very corpulent four and a half years after operation.

Mr. Doran thus reports the ease:-

E.J., aged 49, was admitted into my wards in the Samaritan Free Hospital in November 1903. She had been under the care of Mr. Boodle of Sittingbourne, who informed me that her abdomen had been enlarging for seven years. She had been tapped by another doctor five weeks before admission, and over a pint of ropy fluid had come away without much diminution in the size of the tumour. The periods had been regular until 1902 when they ceased for six months, then a slight show of blood was observed and it re-appeared about every six weeks. I may add that a distinct catamenial period occurred a few days after admission. Mr. Boodle had not detected any evidence of cardiac or pulmonary disease and knew that the patient was of abstemious habits. The girth of the abdomen at the umbilical level a few days before admission was 54 inches. The patient had been married for thirty years and had borne five children, the last confinement occurring 18 years before admission. There had been one abortion only and it had happened between two of her earlier pregnancies. When about eighteen, a year before her marriage, she was laid up with a mild attack of rheumatic fever and, during convalescence, there was, it appears, some kind of relapse which her friends called low fever. She was subject to attacks of bilious vomiting. She declared to me that she had recently lost flesh.

Condition on admission. The patient looked fairly healthy, thin yet hardly cachectic. Both legs were slightly cedematous. The abdomen was greatly distended, the measurements on November 5th being: Girth at umbilical level, $55 \frac{1}{2}$ in.; ensiform cartilage to umbilicus, $16 \frac{1}{2}$ in.; umbilicus to symphysis pubis, $7 \frac{1}{2}$ in.; right anterior superior iliac spine to umbilieus, $11 \frac{1}{2}$ in.; left ditto to 
umbilicus $9 \frac{1}{2}$ in. Thus the girth had distinctly increased since Mr. Boodle had recently taken the measurement.

The integuments of the abdominal wall were neither glossy nor cdematous, and there were no enlarged inguino-femoral glands. There was universal dulness excepting high up in the epigastrium and fluctuation at every point, not transmittible from flank to flank nor from the upper to the lower limits of the tumour. There was a scar below the umbilicus, the result of the recent tapping, and the parietes were much less tense at that point than higher up, as the above measurements showed. This fact suggested loculi.

The uterus could be plainly defined, bulky and anteverted by the tumour, no part of which came down below the brim of the pelvis.

The temperature was normal; the pulse about 84 , small volume, regular. The urine was free from any morbid deposit or albumen; the specific gravity was about 1018.

Operation. On December 1st, 1903, I removed the tumour, assisted by Mr. Butler-Smythe and Captain Illington, I.M.S. Dr. Llewellyn Powell administered gas and ether for the first half-hour and chloroform afterwards.

When the peritoneal cavity was opened, a little fluid escaped, then a very vascular cyst-wall was exposed. The use of the tapping trocar caused severe bleeding. I at once prolonged the abdominal incision to four inches above the umbilicus. The omentum was strongly adherent, with its vessels greatly dilated. An artery and vein were ligatured, the remaining vessels were clamped and the omentum detached and tied in segments. Then $I$ found that four inches of the transverse colon, including the splenic Hexure, were firmly adherent to the cyst-wall, a thin layer of which I detached, leaving it on the bowel which was then set free. I was rather alarmed to find that the under surface of the transverse mesocolon, which adhered firmly to the upper part of the tumour, was torn in two places, but the lacerations were longitudinal and did not involve any of the big vessels.

The fundus of the tumour could now be delivered through the abdominal wound. I broke down several big loculi to make its extraction easier: they were full of pale lymph. One loculus burst spontaneously; it was full of fretid pus.

I now found that the ovaries and Fallopian tubes were separate from the tumour, except that they were connected with it by free, soft adhesions. The tumour sprang from the uterus and from the root of the right round ligament which bore an enormous artery.

Dr. I'owell and Captain Illington transfused a pint and a half of saline fluid under each breast; in the meantime I ligatured the right ovarian vessels, the big artery in the right round ligament and some vessels in the left broad ligament. Then I amputated the uterus above the cervix, one assistant securing the uterine arteries as 
they were divided and the other holding the bulky and heavy tumour till it came away with the body of the uterus and the right ovary and tube. The flap of serous membrame made in front of the uterus during amputation was sewn over the raw surface of the uterine stump. Some large vessels in the right broad ligament had to be secured.

I repaired the two lacerations in the transverse mesocolon and, by means of sutures, carefully turned in the edges of the piece of cyst wall left on the colon.

The peritoneal cavity was flushed with saline fluid, then I applied deep interrupted silkworm-gut sutures to the abdominal wound, flushed the peritoneum once more and lastly tied the sutures, leaving several pints of saline fluid in the abdomen.

The operation took up nearly two hours, but there was no evidence of severe shock when the patient was returned to bed.

The parts removed weighed $15 \mathrm{lb}$.

Description of the parts removed. Dr. Cuthbert Lockyer drew up the following report:-

The specimen consists of the uterus with its right appendages, the latter including a fibroma of the right ovary. The uterus is of the size of two fists. There is an interstitial fibroid in each of its lateral walls, its cavity is elongated and rendered convex on both sides by the bulging of the interstitial growths. The appendages have been removed flush with the surface of the uterus at the left cornu, and at this situation exists a large pedunculated fibroid outgrowth of the size of a Rugby football. From the whole width of the fundus proceeds upwards a cystic fibroid growth of the same size as the enlarged uterus itself.

The right appendages are so distorted at their origin that the Fallopian tube appears to spring from the uterus several inches away from the origin of the right ovarian ligament. The right round ligament bears a small fibroid tumour of the size of a walnut. The Fallopian tube is hypertrophied, elongated and twisted. The ovarian ligament runs into a solid fibrous tumour of the size and shape of a swan's egg.

Microscopic appearances. The large pedunculated tumour presents several areas of what appears to be peritheliomatous change when examined microscopically. Such areas are not to be found in the other tumours.

The mesoblastic changes consist in the appearance of small round cells, which lie in close connexion with numerous blood-vessels and appear in many instances to arise from their outer coats. These blood-vessels have fairly thick walls and are in no sense embryonic like the vessels within a more malignant sarcoma. The new small round cells, however, are indistinguishable from sarcoma-cells, they spread amongst the fibromuscular tissue in columns, they take up 
hæmatoxylin more eagerly than muscle- and fibrous tissue-nuclei, and they show a tendeney to aggregate in patches around bloodvessels like a round-celled inflammatory infiltration, but the cells themselves are larger than leucocytes and do not resemble them in any way.

The fact, Dr. Lockyer adds, that there has been no recurrence since the operation may be accounted for partly by the limited area of the change, many sections showing no sign of the new disease, partly by the pedunculation of the tumour and partly by the fact that peritheliomata are less malignant than the more ordinary types of sarcoma.

Mr. Doran continues : -

Complications during convalescence. During the first week the patient suffered from slight mental disturbance, fancying that her nurses desired to kill her, and there was great flatulent distension on the third day. The pulse and temperature did not, however, rise very high, and the bowels were opened on the fifth day, and there was not any further trouble with them. On the eighth an area of induration could be felt about the seat of the ligatured omentum; on the fifteenth there was a very free discharge from the rectum of a greasy fluid mixed with old clots of a coffee-brown colour. The indurated area, which was palpable on the previous day, had disappeared completely. I suspect that one of the ligatures on the omental vessels, or one of the sutures applied to the piece of cyst-wall on the bowel, had become infected either from the intestine or from the pus which escaped from the loculus which had been tapped. It was not until the twentieth day that the patient began to improve steadily, and I did not think it advisable to discharge her until the middle of January 1904. The abdominal wound had by then healed perfectly, the abdomen was flat, the pulse good and the patient no longer irritable or suspicious. I greatly feared, however, that recurrence would speedily occur, judging from the naked-cye appearances of the tumour and the sections prepared by Dr. Lockyer.

After history. Eight months after the operation, the patient wrote to me saying that she had quite recovered her health, though she still felt weak. Every month a little show appeared, associated with a great deal of pain in the back.

During the Spring of 1905 the patient complained of slimy and foetid vaginal discharge, ultimately a ligature came away and the discharge ceased. By April 1906 she had grown very corpulent, weighing over 17 stone; she was quite able to attend to her household duties. The menopause was not complete until early in 1907. I believe that, considering that the patient was subject to slight mental disturbance, I did rightly in leaving one ovary, but $I$ have discussed this subject elsewhere.*

* "Subtotal Hysterectomy : After-histories of Sixty Cases." Lancet, vol. ii, 1905, p. 1,310, and Trans. Obstet. Soc,, vol. xlvii, p. 363 . 
On April 3rd, 1908, the patient wrote to me stating that she continued to get stronger and was able to take fairly long walks. She was free from any pelvic symptoms. On August 5th she came to see me. She was elearly in very good health. The abdominal walls had become extremely fat and pendulous; the cicatrix of the abdominal incision was free from hermia or new growth. The cervix was small and fairly movable. There was no indication of any new growth or inflammatory deposit in the pelvis or abdomen.

CASE II. Cystic uterine fibroid invading the left broad ligament and sigmoid mesocolon in a secundipara aged 36 . Marked changes in left Fallopian tube and ovary. Deposit in parametrium, of doubtful nature. Uterus amputated above os externum, total. hysterectomy appearing impracticable. Uterine tumours and growths in left tube and ovary malignant (perithelioma) according to microscopic appearances. Speedy recurrence expected, yet patient living and well two years and seven months after the operation.

The following is Mr. Doran's report of the case:-

A.F., aged 36, was admitted into my wards in the Samaritan Free Hospital at the end of May 1905. Fifteen months previously she had discovered a swelling in the left side of the abdomen, and recently it had grown very quickly. The patient stated that she had lost flesh. She had been under the care of Dr. Whittaker of Elgin Avenue, Dr. F. MeCann, and others.

The patient looked very healthy. She was dark-haired, rosycomplexioned, fairly muscular, not stout and in appearance might have passed for a woman of thirty years of age. She had been married for thirteen years, and had borne two children, both in robust health. She had never aborted. The first labour, twelve years before admission, had been scvere and the perineum was torn. The second, five years before admission, was rapid and spontaneous; but the patient was kept in bed for a month for some reason which was not elearly explained to her. "Torn or something," as she expressed it, seemed to imply an injury during the labour; I shall return to the point when describing the condition of the ragina and cervix. There had been no symptoms of pelvic disease since convalescence from the second puerperium. The significance of two normal pregnancies only, at a long interval, in this healthy subject was not clear. Since the first pregnancy the patient had been subject to varicose veins on the outer side of the left leg. Four years before admission, when her youngest child was a year old, the patient had two attacks of "constipation" relieved by enemata. There was no history of any other illness, or of hæmorrhages.

Condition on admission. As above observed, the patient looked very healthy. The abdomen was irregularly distended by a tumour 
which lay more to the left of the middle line than to the right. The integuments seemed healthy, being free from odema or glossiness. The tumour was deeply lobulated; a lobe on the right, somewhat soft, reached above the umbilicus, a still softer lobe made up the entire left portion, a firm lobe lay in the right iliac fossa, and a small, very hard body, could be defined immediately above the pubes, almost in the middle line.

The soft left lobe was very prominent and, on its surface towards the right, was an area of resonance on percussion extending to its upper limits. The entire tumour was movable to a limited extent.

The cervix was vory firm in consistence and continuous with the hard lobe above the pubes. I could not find any laceration, but I detected a suspicious, irregular, bleeding growth on the vaginal wall in the left fornix, possibly the result of some injury during the second labour. I thought, at the time, that it was a malignant growth which had proceeded from the abdominal tumour and perforated the vaginal wall. After repeated examination, however, I found that when the tumour was moved there was no dragging on the left formix. The right and posterior fornices were free.

On cnquiring about the catamenia, I found that they appeared regularly at intervals of three weeks, as had been the case ever since their establishment, and were not associated with much pain. But during the last five or six months before admission they became much more free and a little show had occasionally been noticed between periods. On June 11th, when the patient was under my care, profuse show set in, at the right date. The patient said it was the most severe period that she had ever passed through.

The urine was pale, clear, acid, of low spccific gravity, and even catheter samples contained a trace of albumen. The pulse was 108 , small, not quite regular, and the temperature never rose over $99 \cdot 4$. I could not make out any morbid condition beyond the limits of the genital tract.

The tumour seemed undoubtedly to be a fibroid, the catamenial history confirming the diagnosis, but it was not clear that it was entirely uterine, the resonant tract over the left lobe suggesting intestine pushed up by invasion of its mesentery.

I did not operate until after June 16th, when the show of blood had ceased. In the meantime strychnine and ergot were administered to the patient.

The operation. I operated on June 17th, 1905, assisted by Mr. Butler-Smythe and Dr. Ernest Travers; Mr. A. S. Morley administered the anxsthetic. The pelvis was raised high. On opening the peritoneal cavity, I found the omentum strongly adherent to the surface of the big left lobe. The uterus, very bulky, formed the hard lobe which lay above the pubes. The right Fallopian tube and ovary were seen to be normal. The left tube was very long and thick, 


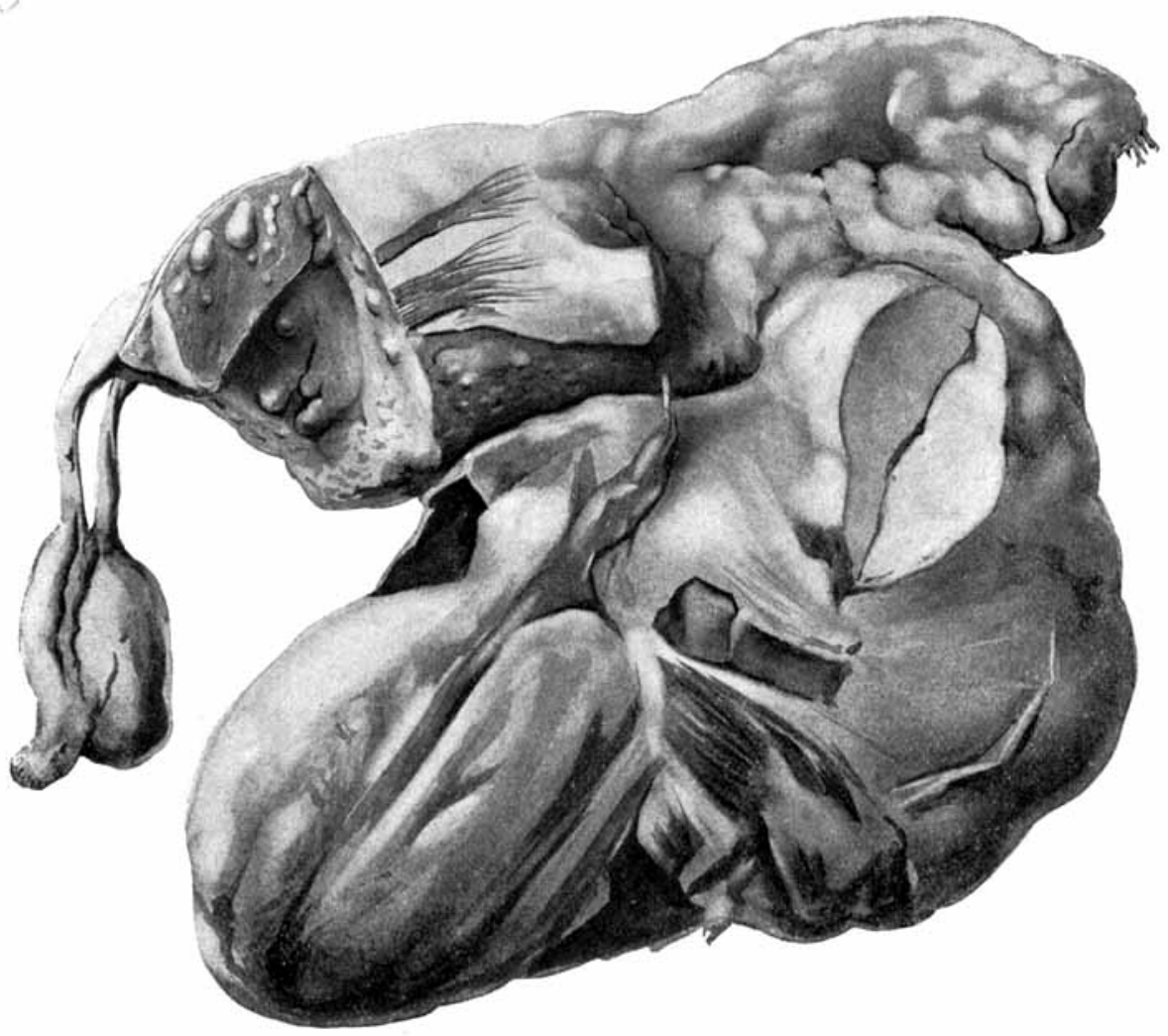

EIG, 1. The uterus, tumour, and appendages from Case ii, showing (1) the appearance of the cystic myomatous perithelioma and its relations to the uterus. (2) The utcrus amputated above the cervix, with deposits of new growth on the cut surface and in the walls higher up, laid open to show the uterine cavity which also bears new growth. (3) The left Fallopian tobe much enlarged and elongated by new growths in its walls.

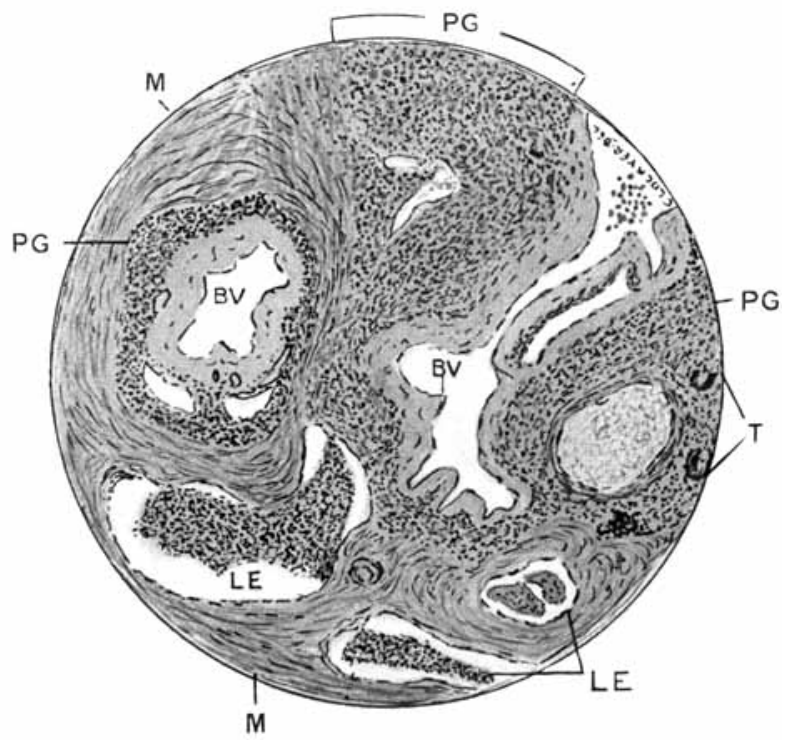

FIG. 2. Section of the tumour. B.V., Blood vessel; L.F., Tymphatic embolus; P.G., Peritheliomatous growth; M., Uterine muscle; T., Tubules from mucasa.

EIgs 2 to 6. Microscopic sections from the parts removed in Case ii, from drawings by Dr. Cuthbert Lockyer. 
the left ovary was somewhat enlarged and closely applied to the big lobe which had opened up not only the base of the left broad ligament, but also the sigmoid mesocolon, so that the sigmoid colon ran down the surface of the big lobe towards the right, accounting for the area of resonance above described. Enucleation of the lobe, the base of which lay very deep, proved difficult. I detached the colon and its mesentery without damage to either, and tied and divided the left ovarian vessels. The whole tumour was thus set free except from its connections with the uterus and left ovary.

The condition of the parts adjacent to the tumour in the left iliac region seemed highly unfavourable. There was deposit in the left parametrium, between the cervix and the bladder and in the left round ligament which was very thick. I tied off the right ovarian vessels, cut through the broad ligament, secured and divided the round ligaments and then amputated the uterus above the cervix, which was fixed by the deposit. The uterine ressels were secured as they were divided; they lay in vcry dense tissue and could not be isolated before ligature in the usual manner. The muscular walls of the uterus appeared very unhealthy, and I could not dissect up a good peritoneal flap anteriorly. I made a V-shaped incision through the uterine walls above the cervix and sewed together the raw surfaces with No. 1 silk in two layers. The omentum, full of very big vessels was resected close to the transverse colon as it was unavoidably damagred when separated from its close adhesions to the tumour. There was much onzing in the left iliac fossa; the peritoneum was flushed with saline fluid, and as the pulse was failing Dr. Travers and Mr. Morley injected several ounces of saline fluid with thirty minims of adrenalin into the right median basilie vein, and liquor strychninæ was administered hypodermically. The abdominal walls were closed in two layers.

The tumour, with the body of the uterus, weighed two pounds and a half. During the enucleation of the big left lobe from the iliac fossa, about a pint of pale yellow thuid escaped from a cystic cavity in its interior. Small solid masses, suggesting myosarcoma, grew from the outer surface of the lolse into the pelvic and iliac connective-tissue.

Deseription of the Parts Removed. The specimen (Fig. 1), Dr. Cuthbert Lockyer reports, is made up of a thick-walled uterus, both appendages, and a large, adherent, partly cystic uterine growth which has burrowed deeply into the left broad ligament. The uterus has not been removed entirc, so that its cut surface presents a very broad base. Its walls vary from one inch to an inch and a lialf in thickness; on section they show numerous small, smooth pea-like growths. Its anterior surface is roughened by recent, deep-red adhesions, especially marked upon the left side.

The right appendages are represented by an elongated Fallopian 
tube, the ovarian ligament, and a cystic ovary. The mesosalpinx and mesometrium are wanting. The left appendages are extensively altered. The Fallopian tube is six inches long and one inch in diameter and is thickened and nodular. The left mesosalpinx is made thick by a nodular solid growth which fuses with the large partly solid and partly cystic growth extending into the parametrium from the left side of the uterus. This growth measures twelve inches by eight by four in its three diameters. Its lower half is cystic and its upper part solid. The cystic portion is rough and devoid of peritoneurn, whilst the upper part is covered by tho expanded left broad ligament. The left ovary is enlarged and on section is found to contain a nodular growth similar to that which invades the tube and mesosalpinx.

Microscopic Appearances. Sections have been prepared from the uterine wall (Figs. 2 and 3 ), the left Fallopian tube (Fig. 4), the mesosalpinx, the left ovary (Fig. 5), the large tumour in the left parametrium, and the left round ligament (Fig. 6). They all show the respective organs and tissues to be invaded by a perithelioma. The cells of the latter resemble in size, shape, and staining characteristics, those cells which make up the lymphomatous stroma of the endometrium. This resemblance is brought into prominonce in the sections of the uterus to which hypertrophied endometrium is attached, and here the new growth fuses with the endometrium as if arising from it. The cells, however, are seen to spring from the adrentitia of the blood-vessels; they form large oval collections, and lie in alveolar spaces amongst the muscle of the uterus and tube. The ovarian deposit consists of a uniform mass made up of oval clusters of these cells with a small amount of connective-tissue binding the clusters together. The same may be said of the structure of the large solid uterine tumour in the left parametrium. In the mesosalpinx are seen large ressels with their lumina plugged by emboli consisting of these small lymphoid-looking cells, but wherever distributed their close connection with the outer coats of the numerous blood-vessels is very apparent.

Mr. Doran continues :

Complications during Convalescence. In this, as in the former case, there was not such speedy uncomplicated convalescence as is usual after hysterectomy for fibroid. When the operation was concluded, I did not expect that the patient would have survived for many hours, as I was under the impression that malignant material had been unavoidably left behind in the parametrium. We all know that when malignant tissue, more or less wounded by the knife and by ligatures, is left within the peritoneal cavity pernicious oozing is liable to occur and speedy advance of the disease is certain. When, most unexpectedly, the patient not only recovered but was restored to her former good health, I never expected that her respite would be 


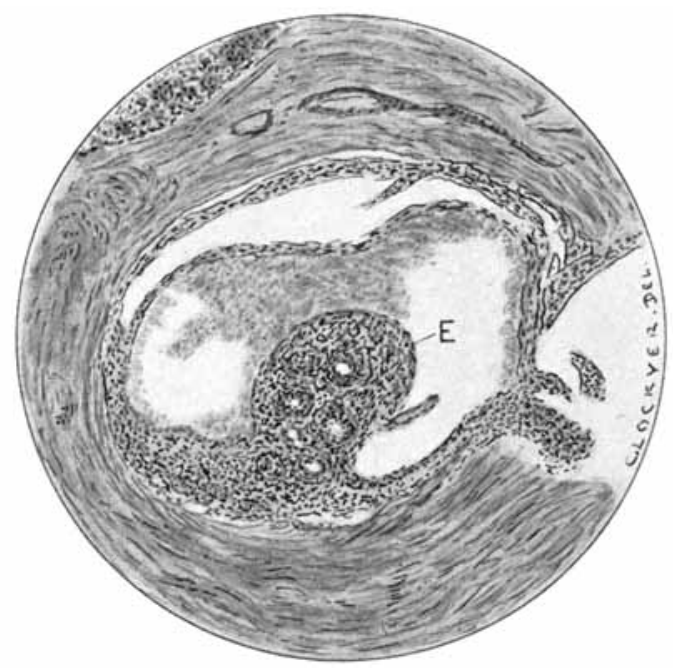

FIG. 3. Section through an intra-uterine blood-vessel showing peritheliomatous new-growth. New-growth protrnding into lumen of vessel.

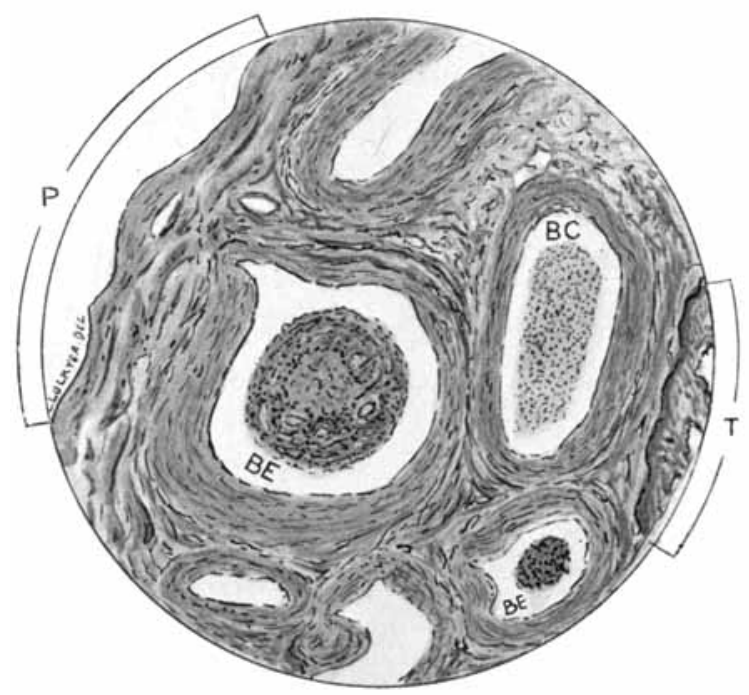

FIG. 4. Section through the left Fallopian tule. B.E., kimbolus of new-growth in blood-vessel. T., Tubal mucosa. P., Tubal peritoneum. B.C., Shrunken thrombus in blood-ressel. 


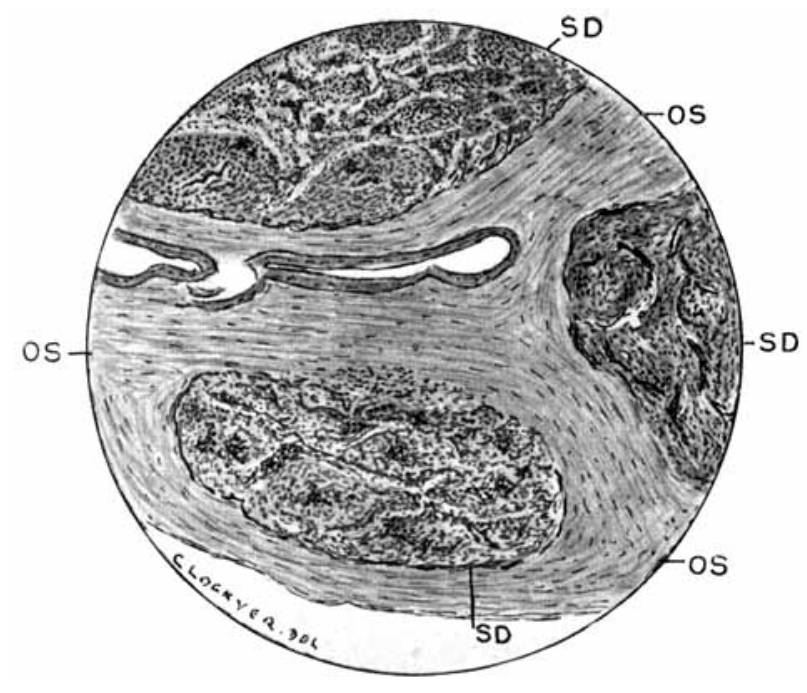

Fic. 5. Section through the left ovary. S.D., Deposit in ovary. O.S., Ovarian stroma.

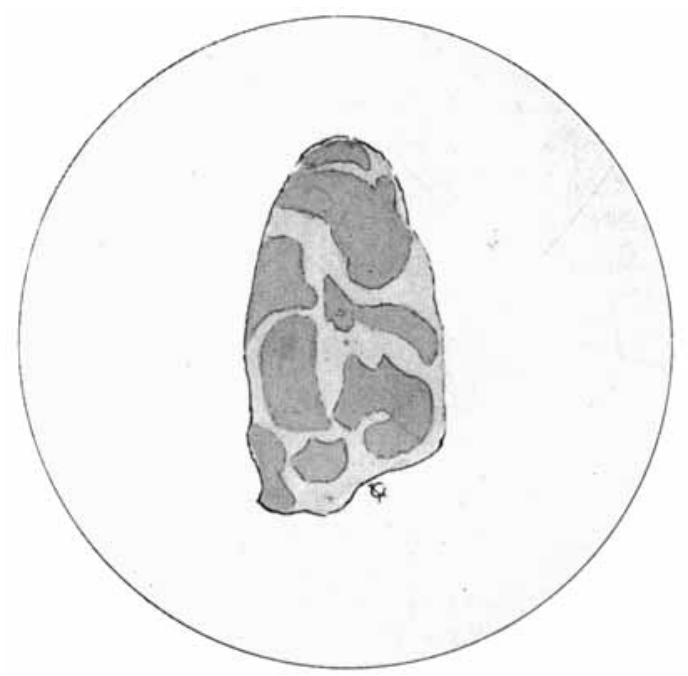

FIG. 6. Section through the left round ligament enlarged to twice the natural size, as seen through transmitted light. The shaded areas represent new growth. 
of long duration. The microscopic appearances so plainly seen in the sections which Dr. Lockyer prepared with great care, indicated malignancy most distinctly. Yet the after-history has up to the present belied our gloomy prognosis.

On the night after the operation, reaction was marked, the patient being slightly delirious. On the afternoon of July 18 an attack of dyspnoea occurred, lasting for forty minutes, the cause of this alarming symptom was not clear. The patient was soon able to take food by the mouth; on July 19 the bowels acted spontaneously, in the night there was slight delirium. On the 20th much solid motion came away after an olive oil enema. The patient had been constipated for months, and although she had been carefully prepared for a fortnight before the operation some old scybala had remained until the oil brought them away. The abdominal wound healed well. On June 23rd the evening temperature rose to $103^{\circ}$, and reached that height every evening until the 29th. This alarming symptom was associated with foetid stools, followed by fœid discharge independent of the motions. The varicose veins in the left leg became inflamed on July 23rd. This troublesome symptom soon subsided, but I felt that the patient's condition was very precarious, and did not allow her to leare the hospital until August 10 th, 1905.

The formidable symptoms were probably due to parametritic inflammation, easily explained, yet it is strange that no suppuration occurred, nor did any characteristic infiltrations in the groin and above the vaginal fornices develop. I ascribed them, at the time, to a much more serious condition, and never expected to hear satisfactory news of the patient after her discharge from the Samaritan Hospital.

After History. To my great surprise the patient came to see me at the hospital on November 2nd, 1905; she had walked over two miles in the rain, yet was not tired, and looked as well as she did before the operation. She complained of attacks of hot flushings and trembling about three times a week and the periods had never been seen since the operation. On November 13th, I examined the patient. The abdominal wound was well healed and there was no deposit to be felt in the parietes nor any tumour to be defined behind them. The cervix was fixed, there was no trace of the bleeding growth on the vaginal mucosa in the left fornix, noted before the operation, but simply a distinet thickening of the vagina bearing two small fleshy wattles. Thus at least there had been no extension of the suspected malignant disease into the vagina. I prescribed ovarian tabloids to relieve the menopause symptoms.

About a year later, I was informed that this patient had died, shortly after the visit to the hospital in Norember, from septic pneumonia following inflammation of the right saphena. This report seemed only what might have been expected, although I remembered 
that the post-operative phlebitis was in the left lower extremity. No doubt, I thought, the new growth had become active and obstructed the veins in the right log.

I continued to watch Case $i$, and to be somewhat surprised at the patient's immunity from recurrence. Yct after all, I had probably removed all the new growth at the operation. In Case ii, it appeared elear that my operation was incomplete. It seemed strange that the patient ever left the hospital alive, but I was not in the least astonished to hear of her death within seven months after the operation. Early last year I intended to publish a parallel between the two cases which would have been most interesting and instructive were it not for the all-important fact that it would have been radically incorrect and misleading. For the second patient was all the time alive and well!

Fortunately I delayed preparing my remarkable parallel. On February 12th, 1908, a patient came to see me at the hospital. She complained of dyspepsia, due, so far as I could makc out, to excessive tea drinking, but added that she had gone on wonderfully well since her operation. Then on looking into my note-book, I found she was Case ii, and there was the report of her death. On further enquiry, it transpired that I had received a false report referring to some other patient who had never been under my care.

The patient looked very healthy, just as she appeared before the operation and had distinctly gained flesh. There had been no period since the operation, and the menopause symptoms had passed away soon after her last visit in 1905. On cxamination, I found the abdominal cicatrix perfectly healthy and the parietes supple. There was no evidence of the existence of any abdominal tumour. The cervix had become very small and was still fixed, the two fleshy wattles in the left fornix had almost disappeared. There was a little resistance above the left fornix just definable in bimanual palpation. The right and posterior fornices were free.

Such was the patient's condition two years and seven months after the operation. In the whole of my operative experience I never came across a case where the after-history so thoroughly belied operative and pathological evidence.

These cases show the imperative necessity for careful observation of all patients from whom uterine fibroids have been removed. Only by such observation can we expect to gain anything like accurate knowledge as to the effects on the patient's organism of the removal of the fibroid uterus, with or without cervical or ovarian tissue, so that we may see how far clinical experience agrees with the physiological experience of Blair Bell, Bond, Carmichael and Marshall and others, and only by such observation can we expect to calculate with something like precision the chances of malignant change being overlooked or misinterpreted. 